\title{
The time based competition paradigm
}

\author{
B. Andries \\ L. Gelders \\ Centre for Industrial Management \\ Celestijnenlaan $300 \mathrm{~A}$ \\ 3001 Leuven - Heverlee \\ Tel.: 32 (16) 32.25.67 \\ Fax.: 32 (16) 32.29.86 \\ bertrand.andries@cib.kuleuven.ac.be \\ ludo.gelders@cib.kuleuven.ac.be
}

\begin{abstract}
In this paper we discuss two important aspects of Time Based Competition: lead time reduction in manufacturing and new product development. In the first part - lead time reduction in manufacturing - we describe an organizational structure that is based on the order penetration point and time, and a technique - Value Added Analysis - that is aimed at the elimination of waste. In the second part we explain how some of the concepts of JIT can be applied to reduce cycle times in new product development.
\end{abstract}

\section{Keywords}

Time based competition, new product development, manufacturing management

\section{INTRODUCTION}

The three C's, customer, competition and change, have created a new world for business. It is becoming increasingly apparent that organizations designed to operate in one environment cannot be expected to work well in another (Hammer and Champy [1993]).

The nature of competition itself has changed: while price, the driving force of the sixties and seventies, is still important, it is often not crucial. Even (product) quality, the paradigm of the eighties, cannot be seen as the major competitive factor anymore. In fact price and quality can be seen as enablers - you simply need them to participate on the market - but leadership will be achieved through other competitive aspects that 
are less related to the product itself but more to how and when the product is offered. Gelders et al. [1995] performed a study within Belgian companies and concluded that the competitive factors, "the winners", could be classified into two broad categories :

- "Quality of logistics". This includes:

- Lead time and delivery reliability. Both are important and interrelated: surveys have demonstrated that (industrial) customers accept longer lead times if (and only if) delivery reliability is assured.

- Service quality. "How is the product brought to us and what can we expect from the supplier during its life cycle?". After sales service, customer complaints, order tracking, quality and customization of packaging, quality of paperwork (invoicing, reports, etc.) are all becoming increasingly important

- Customization. Most cars today are produced on order, Gateway assembles all its PC's on order, ... Benjamin et al. [1995] foresee a future where we will interactively place orders through "information superhighways" directly to the producer. This opens the door to full customization, both in product and service.

- Product diversity. "The ability to rapidly, effectively and continuously introduce quality products that meet customer needs will be the mark of the most successful companies now and in the future" (Choperena [1996]).

When we look closely at these competitive factors we see that one of the common denominators is time. Companies that are able to reshape their processes to fasten the throughput time not only have a time-wise competitive advantage but also obtain a superior performance along other competitive dimensions (price, quality, flexibility, etc.). Many companies have shortened their lead times in the early nineties under pressure of early time based competitors or to be able to meet the constraints of JITdeliveries. The reengineering wave has forced and helped many companies to rethink and streamline their administrative processes. But these are only pieces of the chain linking the supplier to the customer. New battles are now being waged in product development, distribution and service (Blackburn [1991]) on the one hand and into the integration of these time based ideas in the supply chain as a whole on the other hand Within this concept every aspect of the business chain has to be reevaluated, not only from supplier to customer but also from idea to market, from strategy to organizational structure, etc. And all this with only one thing in mind, the customer.

Not all areas are always as important however. Stalk [1993] warned us for the problems related to an exaggerated focus on time in his HBR-publication "Japan's dark side of time". Distribution for example is crucial for a chain of department stores, new product development (and time to market) is crucial in electronics, while manufacturing lead time is essential in production to order companies or JIT-suppliers. But in the automotive sector e.g. all three aspects are of prime importance.

In this paper we analyze the impact of the Time Based Competition (TBC)-paradigm on two parts of the chain : manufacturing and new product development.

\section{TIME BASED COMPETITION IN MANUFACTURING}

A lot has changed in manufacturing within the time span of a single career. In order to understand the difficulties of managers to adapt in the difficult world of permanent (r)evolution it is useful to remember briefly the history of the last 45 years. In the early 
1960 s, because of rising wages and technological innovation, the industrial nations moved into the era of scale-based strategies, using specialized machinery to produce large batches at low costs. Thanks to advancements in computing power MRP systems made their entry pushing materials down the line without too many considerations for capacity except for the fact that time should not be lost setting up the machines. This resulted in huge inventories and lead times, complex materials management but relatively low unit costs. By the mid-seventies manufacturers (mostly in the United Kingdom) adopted a concept developed in the USSR: the focused factory (Skinner [1974]). By focusing on specific products and key elements of production competence, complexity was reduced, thereby enabling these focused manufacturers to attain higher productivity and lower costs than their broad line competitors. Concepts as group technology, cellular manufacturing made their entry. However as product diversity increased and product mix became highly volatile the inherent weaknesses of this production system became apparent: it lacked the volume flexibility to adapt to a changing market. The recognition of this limitation was the driving force of yet another revolution in manufacturing: the introduction of the flexible factory. By successfully introducing flexibility the Japanese were able to abolish the trade-off between scale and variety. This was the beginning of the well documented JIT-era. Finally, according to Stalk [1990] and Blackburn [1991] the ability to produce many different products within short time spans created the need to introduce even more products at faster rates and to reduce lead times accordingly in the other areas of the supply chain (distribution, administration, ...). This means TBC in manufacturing inevitably relies heavily on the concepts of the flexible factory and JIT.

\subsection{Time Based Manufacturing Logistics}

Variety and availability are important factors in today's markets. Customers want a vast spectrum of products and they want them now! But how do producers have to adapt? Both factors are contradictory from a producer's point of view : variety means that the number of different products is high while availability means (traditionally) that you have to keep these products in stock. When the number of products increases, the number of products in inventory increases and hence the inventory value (and cost). The reliability of the forecasts will decrease with the number of products to be forecasted. As a consequence the amount of unsold and obsolete inventory will increase together with the stock-outs. Moreover, increased diversity means production in small batches which increases the proportional part of setups and lowers overall productivity.

This spiral of increasing logistic costs and decreasing efficiency can be avoided. The answer lies in redesigning the logistic chain towards responsitivity and lean production: a good localization of the Order Penetration Point (OPP), a Time Based Strategy (TBS) downstream the OPP and the use of concepts like commonality, load and throughput oriented order release are key factors in this process (Andries \& Gelders [1995]).

The OPP is the stage in the production line from where production is on order. Production in front of the OPP is for general purpose and based on forecast while every part produced or assembled behind the OPP is dedicated to a customer.

When the OPP is located close to the end of the line customer demand is fulfilled from inventory. Inventory replenishment and production planning are based on forecast of demand during lead time. The safety stocks are high because they are proportional to uncertainty about customer demand and production lead times. When the OPP is moved 
to the beginning of the line production is on order. Inventory of finished goods is low (or non-existent) but customer service is critical. Manufacturers who assemble to order typically have their OPP situated somewhere in the middle of the supply chain.

When deciding about the location of the OPP one has to take two opposite forces into consideration : the delivery times imposed by the market and the inventories.

When a company's order cycle time (i.e. the lead time from OPP to customer) is longer than the market delivery time, this company will tend to react by moving the OPP (= its inventories) downstream (i.e. closer to the market).

Raw material inventories are cheaper than end item inventories. From an economical point of view it is interesting to move the inventories upstream. But how far upstream ? A obvious solution is to locate the OPP at the convergence point of the Bill Of Materials. This convergence point is located at that place in the supply chain where the amount of parts, components, sub-assemblies or assemblies is the lowest. The exact location of this point depends of the type of industry. There are three basic types (Figure 1 and Table 1):

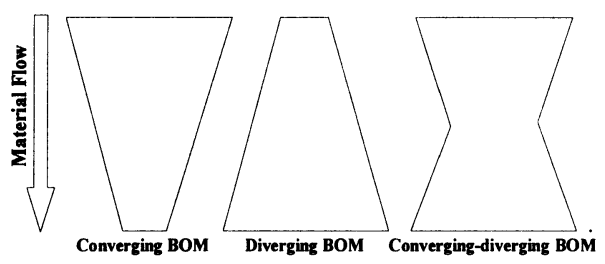

Figure 1

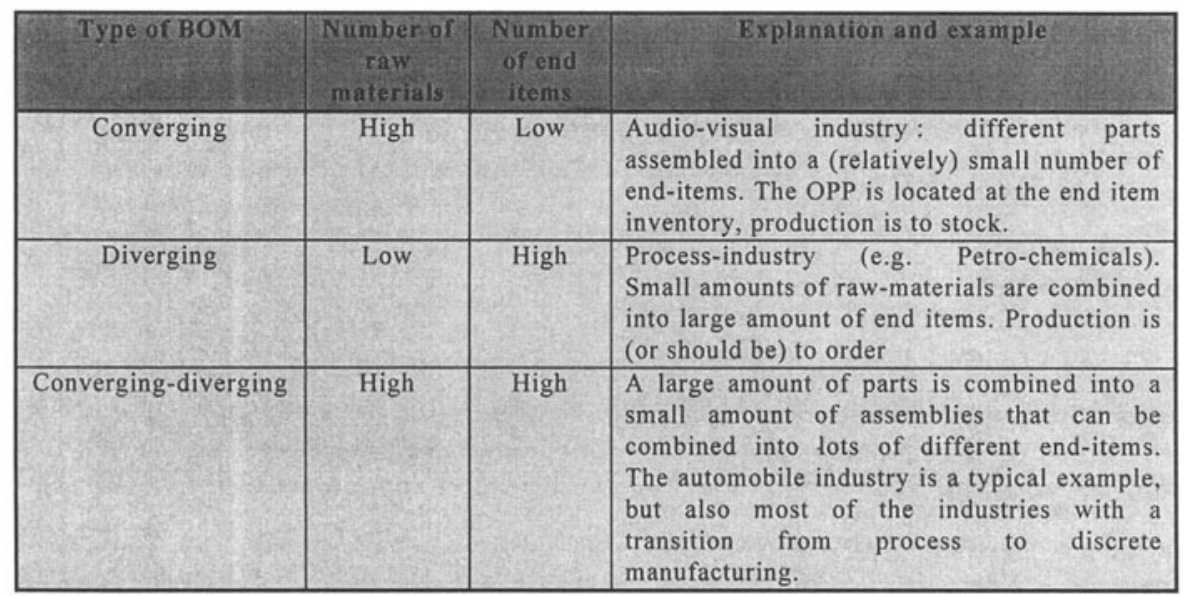

Table 1

Based on the concept of the OPP a strategy is developed. The idea behind this strategy is that not all the parts of the supply chain have to be totally focused on time but only 
these parts that are visible for the customer. In the other parts lead time reduction is to be seen as a means of cost reduction and not as an objective in itself.

Figure 2 illustrates the concept of a strategy based on the OPP and time. The supply chain can be divided into three distinctive parts, each with specific characteristics and objectives. First we shortly describe the different parts. Control methodologies will be dealt with in the sequel.

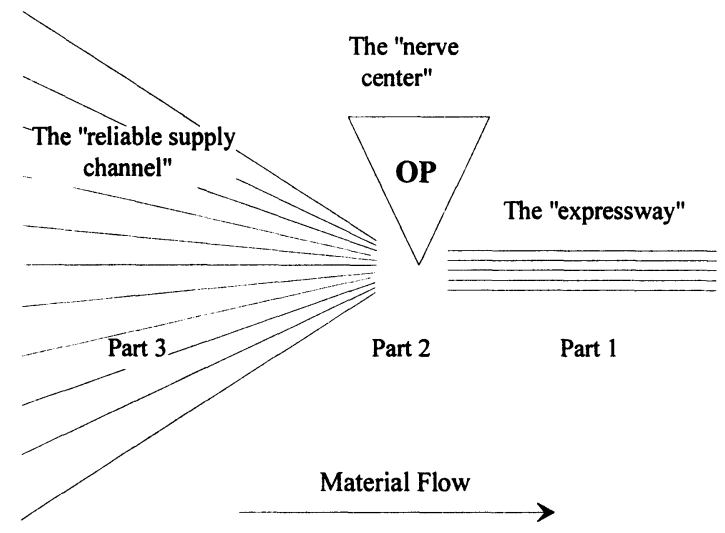

\section{Figure 2}

The "expressway". Production is on order. Delivery reliability, responsitivity, throughput and speed are the key issues. Lead time reduction is automatically translated into an equal reduction of delivery time. The control methodology is specifically designed for these characteristics.

The "nerve center". Within a time based strategy, all control and production management must start from this point : the performance of the downstream part (the expressway) depends on the material availability at this point

The "reliable supply channel". Delivery reliability is the key issue. Production is based on forecasts. Both lead times (because of cycle stock and forecast accuracy) and lead time variability (safety stocks) are important.

We can now discuss the production control strategies in the different parts of the chain.

\section{A. The Production downstream the OPP}

The control and planning of this part of the line depends on the OPP. The objectives of the planning is to maximize the service level while keeping the lead time beneath the promised lead time (imposed by the market). Four concepts are of prime importance here :

a) Setup and lotsize reduction

b) A flow oriented manufacturing layout

c) A high VAT (Value Added Time) / lead time value.

d) A low variability in the material flow

e) A dynamic priority system based on due dates

We discuss topic $a, b, c$ and $d$ and we refer to the scheduling literature for topic e. 
a) Setup and lotsize reduction

Setup times are an important driver of lead times and flexibility. Basically the cost of variety is the cost of setups. Eliminate the setups and the cost of variety disappears.

Machine changeovers are not standardized activities in most factories. According to the SMED-principles (Single Minute Exchange of Die), a setup should be a well considered task, like any other process in production. SMED is a method to reduce setup times. The standard procedure for SMED analysis is very easy to understand and doesn't require long training to perform. The implementation steps are very similar with Deming's famous "wheel for quality improvement". The procedure can be summarized into four steps: planning, observation, analysis and action.

In the planning stage, a planning team is formed and goals are specified. Both top (production)management and setup- and machine-operators should be part of the team from the very beginning of the SMED-project. Management participation is important because SMED will involve machine downtime and loss of production and eventually investment. Workers participation is important because they will have to perform the setups. Early involvement is recommended to make them understand the reasons and motivations of the SMED program.

In the next phase, the actual setup is observed. This observation is usually based on a video recording of the setup. A detailed description of the different setup operations is added to the visual record. The analysis phase starts with a time and method study of the operations. Every activity should be broken down into basic motions before the SMEDanalysis can start. Shigeo Shingo [1985] distinguished 5 basic principles :

1. Classify internal versus external activities. Internal activities are activities performed while machines are down. External activities may be performed while the machine is operating.

2. Complete external activities prior to setup (while the machine is running). Moving all external activities from in-line to off-line can result in substantial reduction of setup time (Shingo reports savings from 30 to $50 \%$ ).

3. Convert internal to external activities by modifying the setup organization. One technique is to double pieces of equipment. Perform the setup on one piece while the other is running.

4. Install parallel or simultaneous operations. This usually involves adding manpower.

5. Smooth and simplify the setup. In this phase training and teamwork and technical improvements are essential.

The goal of principle 1 to 3 is to reduce the tasks that must be carried out while the machine is down. Principles 4 and 5 minimize the time while the machine is down. One should notice the extreme simplicity of the principles. Most technical and organizational improvements suggested by Shingo require very little research or investments ("Simplify first, then automate."). Setup time reduction is the first step to continuous improvement. Once batch sizes and hence WIP is reduced other problems will show up (according to the "water and the rocks" analogy). These problems (the rocks) will prevent further leadtime reduction. The rocks on the factory floor are layout, quality and planning. 
b) Flow oriented manufacturing layout

Large batches cause high work in process. Work stations tend to look like islands surrounded by oceans of inventory. The consequence is a slow and jerky flow of materials through the factory. Machines don't have to be connected nor synchronized because of large buffers which make control superfluous. The distance between work stations becomes very large and communication is reduced to a minimum. Many classical factories are organized in process-centers. Products are brought from process to process along complicated routings. Space, time and inventory have become insurmountable obstacles for local communication between work stations and divisions. Performance is measured by local performance measurement systems which strengthen the sub optimality of the systems. Centralized computer control becomes unavoidable.

Small batch sizes and frequent changeovers rectify these drawbacks. Oceans of inventory disappear, space is created and work stations can be moved closer. With connected instead of isolated work stations, a synchronized material flow becomes possible. Parts are manufactured and moved to the next station when they are needed. Downstream demand pulls the parts and the components through the manufacturing system. If demand is not too variable and a limited number product families can be identified (based on low changeover times within the family and/or similar routings) the factory can be divided into parallel flow lines which simplify the task of planning and (potentially) reduce lead times even further thanks to elimination or reduction of the setups within the product class. A good example of this strategy was given by an electronic component manufacturer in Belgium. Historically the layout of the factory had been organized as a job shop. However faced with an increasing number of products $(>300)$, long changeover times and an explosion of packaging possibilities $(>50)$ planning became difficult if not impossible to manage. Careful examination of the product mix and routing permitted to identify 5 product families for production and 3 families for packaging. Reorganizing of the job shop into a flow shop with 5 parallel lines permitted to reduce lead times (and WIP) by $75 \%$. Only one additional machine had to be bought and 3 lines had to share to 2 bottleneck machines. Three flexible packaging machines were also bought. The space freed permitted to move the raw material inventories from the outside warehouse into the plant facilitating material handling and control.

c) A low VAT/lead time

The Value Added Time is the sum of the processing times of the value added steps. We will further discuss a technique aimed at increasing the ratio VAT/lead time. In this paragraph we describe an order release strategy that leads to better lead time control.

The ratio VAT/lead time is maximized by (among other things) reducing the queueing effect to its minimum. But one should be cautious when increasing the fraction. Limited queues are necessary to keep machine utilization at acceptable levels. A realistic target level for VAT/lead time lies between 0.25 and 0.4 . Queue time can be limited by keeping WIP levels under a certain (low) level. The amount of WIP on the other hand is strongly dependent on the company's release strategy (Figure 3) : 


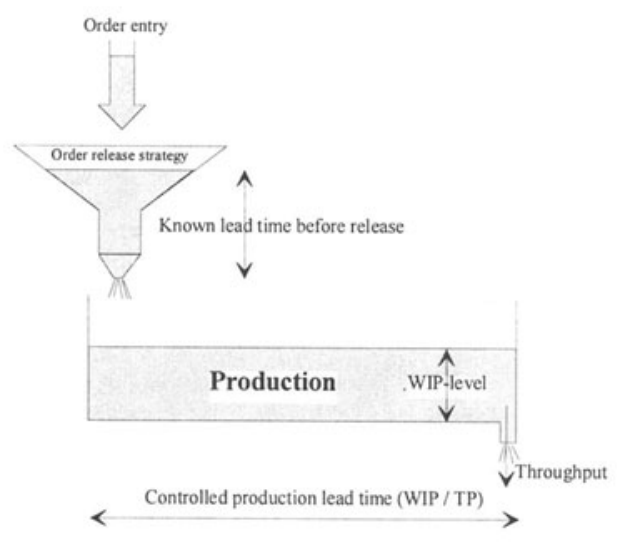

\section{Figure 3}

The principles of this methodology are very easy to understand (Wiendahl et al. [1992]). The production lead time is directly proportional to the amount of WIP (Little's law : lead time $=$ WIP / throughput). If WIP is kept low and constant then lead times will be short and constant (and vice versa). Moreover with low WIP, control of material flow is facilitated, priority rules are easier to apply, costs of non quality are reduced,...i.e. variation is reduced and predictability is increased.

The consequence of reduced WIP on the production floor is an increased backlog of orders in the planning phase. But this has advantages too : customers order changes have less influence on production, priorities can be changed before order release, etc.

The planning lead time can be calculated too (backlog / throughput). This means that reliable approximations of total lead times can be calculated and delivery dates agreed upon with the customer. Order tracking is simplified by transparency both in planning and production lead time.

d) Material flow variability

Material flow variability has a strong negative impact on production lead times. It can be shown that interarrival time variability and process time variability have a dramatic impact on lead times.

But processing and arrival variability are not the only type of variation in production. We also have :

Machine - breakdowns influence the material flow in different ways :

- it reduces global capacity, directly in case of a bottleneck machine, indirectly if it causes starvation of a bottleneck machine

- it creates a lumpy material flow that results in WIP concentration at some places and starvation at other places

- it increases the amount of WIP : companies with unreliable machines tend to release more orders to avoid starvation ("raise the waterlevel to hide the rocks").

Synchronization problems are caused by missing parts at assembly stations. Many manufacturers "solve" this problem by increasing buffer capacity.

Customer order changes interrupt the processing. They have a highly disturbing effect when they occur during the production phase. It also originates a negative spiral : 
planning will release more orders (i.e. more WIP) to avoid idleness when order changes are frequent. This increases lead times which increases the probability of changes occurring in the production phase.... This spiral can be reverted into a positive one. If WIP is kept low, most changes will occur during the planning lead time.

Material availability is one of the key issues of the planning at the OPP : "Do not release an order unless all parts are available". Some companies disassemble less urgent orders (cannibalization) to obtain the necessary components. The consequences of this policy on the material flow should be clear....A better solution is to add a "throughput module" to the planning software. This module selects orders from the order list as a function of the material availability and the due date. A printed circuit board manufacturer in Belgium dramatically improved its lead time performance after installing a "throughput optimizer" that checked component availability before release for its 2000 different PCB types.

Any lead time reduction program that fails to recognize the importance of these factors is bound to have only marginal results.

\section{B. OPP inventory management and production upstream the OPP}

Key issues here are forecasts, inventory policies and cost reductions. The first aspect is important for the production in the supply channel while the second factor determines the number of different components and the quantity of each component to be kept in inventory at the OPP. Both must be focused towards maximum material availability at the OPP at reasonable cost (third factor). In the remainder of this paper we suggest solutions to those problems.

\section{a) Forecasts}

The accuracy of forecasts depends mainly on three factors :

1. The forecast technique. The number of available techniques being almost unlimited, we refer to specialized literature.

2. The number of products to be forecasted.

3. The forecast horizon. Forecast accuracy decreases when the horizon increases. The forecast horizon corresponds to the delivery lead time of the supply channel.

We will come back to point two later. Point three is important because little attention has been paid to lead time effects on forecast accuracy until now. Most production and inventory models (or lotsizing models) are based on the "best" trade-off between inventory and setups (e.g. economic order quantity models). Lotsizes increase when setup costs are important also causing WIP and lead times to increase. Long lead times increase the forecast horizon hence reducing forecast accuracy. Reduced forecast accuracy is automatically translated into an inventory problem at the OPP. This increases costs and reduces material availability at the OPP and hence overall reliability of the supply chain. Lead time related costs should be included in the lotsize calculations. This can be achieved by including lead time effects into the lotsizing calculations and adding a forecast inaccuracy cost that depends on the lead time.

b) Inventory policy at the OPP

The key aspect here is material availability. Three questions remain to be answered :

1. Which items/components/parts should be kept in stock ? 
2. Is it possible to reduce the number of different items?

3. How many of each item should we have in stock?

The most important issue in choosing which items to keep in stock is the material availability as a function of the end product. We have mentioned yet that component availability was a conditio sine qua non for order release. This means that the only way to realize a short delivery time is to keep the components in stock (or to work on a JITbase with the suppliers). Question one can thus be stated differently: for which end items do we want short delivery times? Though this depends on the policy of the company, we think that every company should consider how far it is prepared to go to fulfill customer requests. Is it rewarding to keep components in inventory for every "exotic" product type ? Has the company any idea of the cost of short delivery times for those products? Techniques like Activity Based Costing help to provide answers to these problems. These techniques attribute logistic costs to the products that drove those costs, providing arguments to remove components of slow moving, high cost products from stock. Another valuable tool is the PARETO-analysis that highlights the important segments of products from the great majority of less significant items. One could say, as a general inventory policy, that no components should be kept in stock for the last 5 or $10 \%$ of demand (unless the component or end item is needed for strategic reasons). This means that the end item demand and the logistic costs determine whether a component will be held in stock or not.

As a consequence of this policy there will be two OPP in the line : one located before the assembly stations and responsible for (e.g.) $90 \%$ of turnover and one situated at the beginning of the supply chain (raw materials) dedicated to end items with low demand (and long delivery times).

Another helpful technique to reduce OPP-inventory is standardization and commonality at that point. Commonality is achieved by using common components for different end items. Though commonality is important in all parts of the supply chain, it is at the OPP that the biggest returns can be achieved.

The last point of interest in this part of the chain is production control. Production to forecast, focuses on material availability and the (usually) large number of parts makes this part of the chain especially suited for a MRP(II) type of control. On the other hand, pull systems can be utilized for components with stable demand (especially those with a high degree of commonality). We think MRP(II) production control combined with JITaspects for components with stable demand is the best type of control for this part of the chain.

\subsection{Value Added Analysis (VAA)}

Value added analysis is a straightforward method aimed at reducing waste(d time) in the supply chain. This is done by focusing on the value adding activities in the supply chain and by trying to eliminate all activities that do not add value to the product or service. But, ... before a company can start with the elimination of waste, a thorough definition of value and value added (time) should be provided.

The most common definitions assume that value is added to a product whenever the product undergoes a transformation (that is valuable for the customer) or when a product is brought closer to the customer. Every operation that cannot be included in these two 
classes is wasteful and should be eliminated or at least reduced. But one should be very careful with the classification of value-added activities. Each step must be critically evaluated: is this step really value adding ? Can't we avoid or simplify it? Table 2 provides a few examples of traps to avoid.

\begin{tabular}{|c|c|c|}
\hline Step & Value Added because: & $\begin{array}{l}\text { NOT } 100 \% \text {-Value Added } \\
\text { because: }\end{array}$ \\
\hline $\begin{array}{l}\text { Product quality } \\
\text { inspection }\end{array}$ & $\begin{array}{l}\text { Product of unknown quality is } \\
\text { transformed into a product of } \\
\text { known quality }\end{array}$ & $\begin{array}{l}\text { Inspections are superfluous if } \\
\text { process reliability is high ("zero- } \\
\text { defect") }\end{array}$ \\
\hline $\begin{array}{l}\text { Two serial production } \\
\text { steps }\end{array}$ & $\begin{array}{l}\text { The steps are needed to } \\
\text { manufacture the product }\end{array}$ & Could both steps be combined? \\
\hline One production step & $\begin{array}{l}\text { The step is needed to manufacture } \\
\text { the product }\end{array}$ & $\begin{array}{l}\text { Could the step be avoided } \\
\text { through e.g. Design for } \\
\text { Manufacturing? }\end{array}$ \\
\hline One production step & $\begin{array}{l}\text { The step is needed to manufacture } \\
\text { the product }\end{array}$ & $\begin{array}{l}\text { Is the step performed at nominal } \\
\text { capacity? }\end{array}$ \\
\hline Material handling & $\begin{array}{l}\text { Products must be stored or } \\
\text { transported to the next } \\
\text { workstation }\end{array}$ & $\begin{array}{l}\text { Why does the product need to be } \\
\text { stored? Is it possible to place } \\
\text { both workstations next to each } \\
\text { other? }\end{array}$ \\
\hline
\end{tabular}

\section{Table 2}

Once value has been defined within the company the actual value analysis can start: as Shapiro put it in his 1992 paper: Staple yourself to an order.

Time and efforts are wasted in the supply chain. Typical values of VAT-ratio's (= the sum of the value added processing times divided by the total lead time) range from 1 to $5 \%$. This percent is even lower if products are considered instead of orders or lots and if end item inventory turnover is included in the total lead time. This means that an order spends at least $95 \%$ of its lead time waiting for value to be added. If one wants to reduce lead time one must work on these $95 \%$. Lead time reduction by increasing production speeds only affects $5 \%$ of the total value. The problem is we can work twice as fast but we can't wait twice as fast!

The best way to identify these $95 \%$ is to "staple" yourself to an order and follow it through the whole supply chain from order entry to delivery (in most cases it will even be useful to backtrack the order up to the MPS cycle or the raw materials forecast).

This approach is necessary for two important reasons :

1. The contradiction between horizontal product flows and vertical organizational structures:

- The products flow horizontally from one department to the other while the information flows through the hierarchical decision structure causing delays and incompatibilities.

- Vertical knowledge gaps. The only persons who can oversee the whole supply chain are high in the hierarchy, meaning that they have a strongly simplified view on the process while operational people only have a limited view on the chain. 
2. Prioritization. It is only by following the order that one can understand the importance of priorities on lead times and especially lead time variation.

We believe that traditional process mapping techniques (Data Flow Diagrams, flow charts, ...) will often fail to reveal these (very important) lead time influencing factors because they rely too much on people's view on the process which is fundamentally different from the process seen from a product's perspective. DFD's do not include a time dimension while flow charts only include a sequence of events and not the timing of these events.

When one looks at the process from a product's perspective one will invariably notice that the flow of the order consists of an endless repetition of the same building block: a tandem queue. This block is represented in Figure 4:

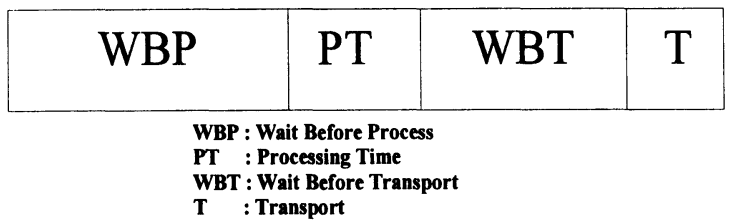

\section{Figure 4}

- Wait before process (WBP) consists of queuing before a "workstation" (machine, manual process, administrative process,...). It is NON value added. Usually the sum of all WBP's is responsible for more than $75 \%$ of total lead time.

- The processing time (PT) is the time during which the product is "transformed", and is therefore value added. If a value added process is eliminated (e.g. by better design), all the other components of the tandem queue disappear, resulting in substantial lead time reduction.

- Wait before transport (WBT) is the time a product has to wait before it is moved to the next "workstation". It is NON value added.

- Transport is the action of taking the product to the next workstation. Transport can be achieved by material handling systems but also electronically when the workstations are administrative systems (in this case the product is information). If the next "workstation" is the customer, this step is value added. In most other cases it is not adding value.

The whole actual value analysis can then be divided into 4 remaining steps : orderstapling, identification, improvement and iteration.

\section{A. Order-stapling}

As has been said, the order must be followed from its first appearance in the company until it has left the system (or until the order is paid if financial cycles are investigated too). Shapiro [1992] distinguishes 10 different steps in the order management cycle: 


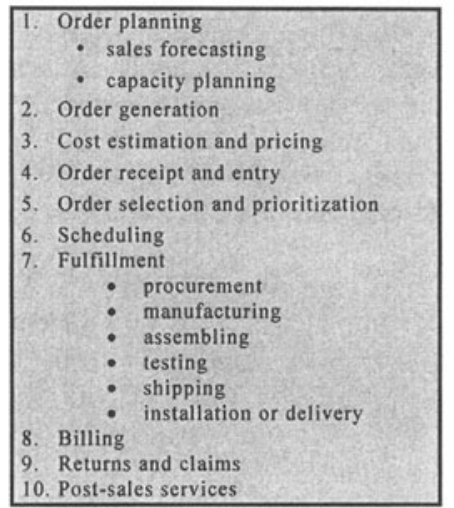

\section{Table 3}

This presentation is interesting because the classical "order cycle" only starts from step 4. In the remainder we will pay no further attention to steps 8 to 10 .

Steps 1 to 3 are important, but difficult to trace because they happen before the actual order is even placed.

When performing a value analysis it is recommended to follow the order "on the floor" personally. But one must be careful. It does not mean following the "physical" order, wherever the product is but "following the logical order on its critical path". Figure 5 illustrates the difference between the "physical" flow of the order and the logical flow :

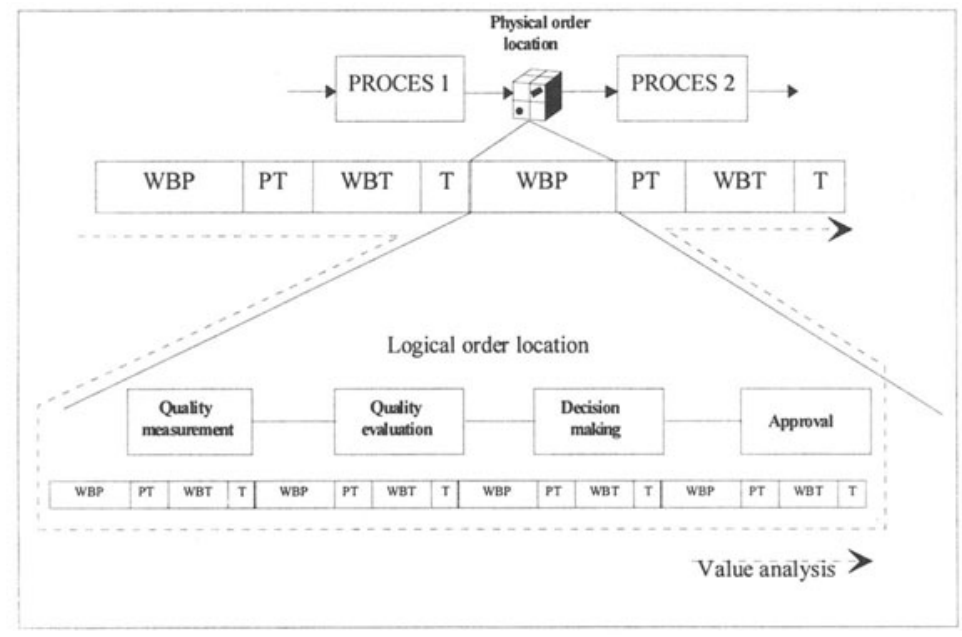

Figure 5

While the order is waiting on the production floor a sample is sent to the quality department for inspection. The logical location is then at the quality department and the 
value analysis must follow that flow. When two processes are in parallel the critical path should be followed.

Once all paths are identified, follow-up documents can be designed to perform further data gathering. Four control points are needed for every tandem queue that must be measured (one at the end or the start of every component of the queue). If the processing times are known and processing time variability is negligible, three measurement points are sufficient.

Figure 6 shows an example of an analysis performed at a chemical plant. This part of the study involved 12 operations performed in 9 different activity centers (called departments). 36 measurement points were required in the first phase (identification of opportunities) of the lead time reduction project. These 36 measurements were reduced to 25 to be registered using 3 different follow up documents. After the identification phase, 9 control points were chosen to monitor improvements. These points were necessary to be able to recognize individual department responsibilities in the improvements.

Three product families were identified based on routing characteristics. Two orders of each family were personally (and concurrently) followed to identify critical paths and design proper follow-up documents. 36 orders were then traced with the documents resulting in the data shown in figure 5 . From the lead time and VAT / LT figures planned lead times were chosen as objectives for the lead time reduction.

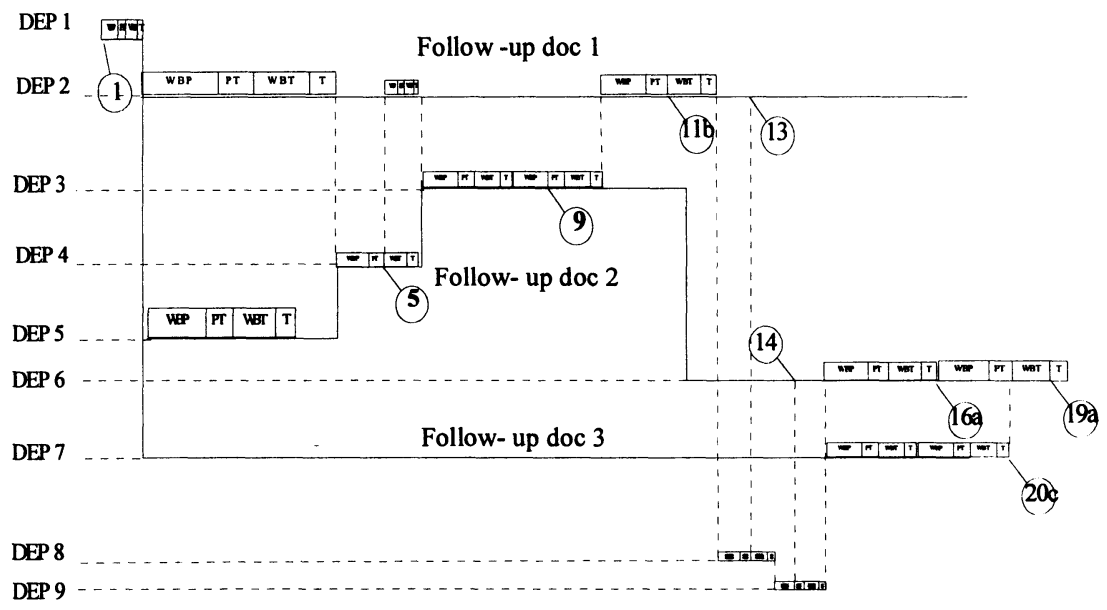

\begin{tabular}{|l|c|c|c|c|c|c|c|c|}
\hline From $\rightarrow$ To & $1 \rightarrow 5$ & $5 \rightarrow 9$ & $9 \rightarrow 11 \mathrm{~b}$ & $11 \mathrm{~b} \rightarrow 13$ & $13 \rightarrow 14$ & $14 \rightarrow 16 \mathrm{a}$ & $16 \mathrm{a} \rightarrow 20 \mathrm{c}$ & $20 \mathrm{c} \rightarrow 19 \mathrm{a}$ \\
\hline $\begin{array}{l}\text { Actual LT } \\
\text { (days) }\end{array}$ & 6.4 & 1.81 & 0.34 & 2.33 & 0.45 & 18.30 & 1.76 & 1.93 \\
\hline VAT / LT & $17 \%$ & $\begin{array}{c}0.6 \\
\%\end{array}$ & $5 \%$ & $7 \%$ & $42 \%$ & $93 \%$ & $0.01 \%$ & $26 \%$ \\
\hline $\begin{array}{l}\text { Planned LT } \\
\text { (days) }\end{array}$ & 1.5 & 0.5 & 0.3 & 0.5 & 0.45 & 18 & 0.5 & 1 \\
\hline
\end{tabular}

Figure 6 


\section{B. Identification}

Now, the best opportunities for lead time reduction can be identified. This identification can be made by means of two proactive diagnostic performance measures :

- Lead time

- Ratio VAT/lead time

Both measures can be used for single processes ( 1 tandem queue), groups of processes or even complete departments or plants.

The first measure states where the greatest absolute lead time reduction can be achieved while the greatest relative opportunity is given by the second measure.

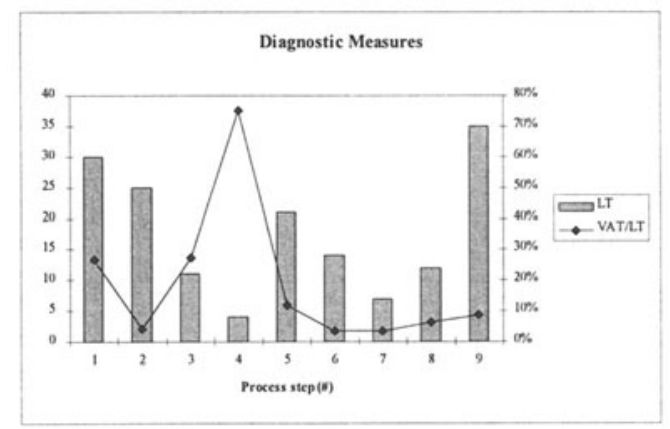

\section{Figure 7}

From Figure 7 we see :

- Processes 1, 2 and 9 give the best opportunities for absolute lead time reduction

- Processes 2, 6, 7, 8 and 9 give the best opportunities for relative lead time reduction

- No significant lead time reduction can be expected from processes 3 and 4

- Conclusion : processes 2 and 9 are the ones to start with

It is important to remark that the ratio VAT/LT is meant as a diagnostic performance measure (i.e. to determine where improvements can be made) and not a control measure (i.e. to control the improvement process) because improvement could impact both the nominator and the denominator. Lead time (or VAT) can be used for both purposes, diagnostic and control.

The next step is the identification and the removal of the causes of waste. Although this step is probably one of the most important ones it is also highly case dependent and difficult to discuss in general terms. We therefore refer to the case study literature. 


\section{TIME BASED COMPETITION IN NEW PRODUCT DEVELOPMENT}

Traditionally Western management has always assumed that there is plenty of time for new product development : all options were taken into consideration, all alternatives were generated and evaluated, different scenarios were played off and tons of reports had to go up and down the hierarchical structure of the company. But meanwhile product life cycles kept shrinking and Japanese competitors were introducing cheap and high quality products much faster than before. This led to a situation where the product development cycle exceeds the life cycle of the previous generation and where Western companies lost market share to the Japanese. Figure 8 illustrates the evolution of the PLC in the computer industry

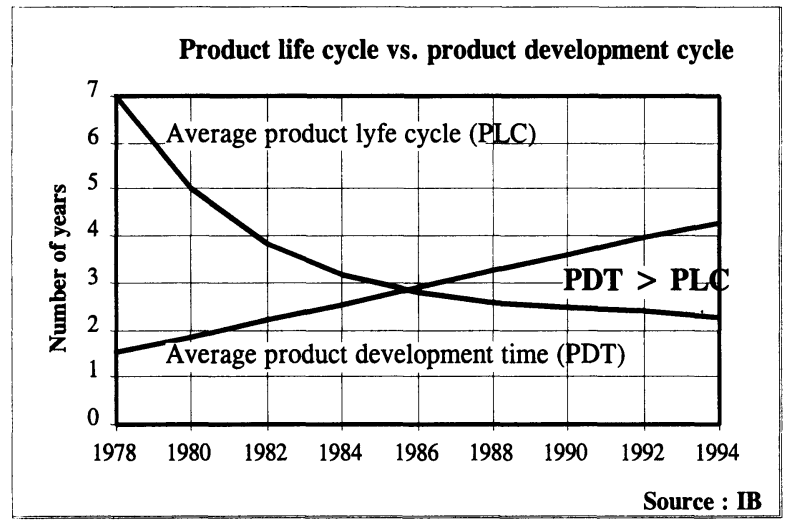

\section{Figure 8}

A time based focus has to be introduced in the whole supply chain including new product development

One of the key characteristics of Time Based Competitors is their ability to get new products to the market before their competitors can. They create products which often provide value exceeding customer demand and they make a profit doing so.

A comparison of Japanese and Western companies (especially in engineering intensive organizations) reveals that their new product introduction rate is a few times higher than their Western competitors. Clark [1987] stated that the Japanese can develop a new vehicle about 18 months faster than Americans. The product life cycle of an automobile has an average duration of about 6 years. It is easy to understand the competitive advantage of Honda for example who brings a new car to market every 4 years on average. And indeed, late market introduction can cause severe loss of returns. Mc. Kinsey and Co. [1985] reported that a 6 month late introduction can cause a $33 \%$ decrease in net profits. Another known and painful example are FORD's billions of dollars of lost revenue due to the late introduction of the Mondeo as a replacement of the aging Sierra.

Research on fast product development is still in an embryonic stage. The different principles which lead to time compressed manufacturing processes are well known, some of them were described in the previous paragraphs. The same guide-lines for new 
product development seem to be non existent. However a few concepts seem to crystallize :

1. The necessity of an environment focused on change and innovation

2. The use of information technology which providing the most performing design tools.

And also, according to Christopher Meyer [1993]: "The only way to increase profit and reduce costs, while concurrently improving product development speed, is to fundamentally change the product development process itself."

The Japanese quickly noticed that the very same JIT-ideas that had been successfully used in manufacturing could be transposed to NPD. Indeed the JIT-model is very attractive for new product development. First of all, the basic goals of JIT - the elimination of waste, simplicity, total quality and speed - are key attributes in all parts of the company. Second, the experience gained in production can be transposed to new product development. Third, JIT incarnates the KAIZEN principle of incremental and continuous improvement. The model for the management of the NPD presented in the following is a translation of some the JIT-principles to the development phase.

\subsection{Concurrent Engineering}

In most Western companies new product development consists of consecutive or serial steps. In the very first stages design-engineers are responsible for the conceptual design and the drawings. The blueprints and/or the prototype are delivered to the production engineers to prepare large scale production in a next stage. After this step the people of planning and logistics are asked to join the project to prepare the bill of materials and resolve inventory and capacity problems. In the last phase marketing and sales perform the market introduction. This phased approach of product design, development, manufacturing and marketing has important drawbacks. One problem is the very long product development cycle. Another problem lies in the fact that $90 \%$ of the budget costs are sunk before production engineers get involved in the process. Lack of market feasibility due to late involvement of marketing is the third drawback.

The major drawbacks of "consecutive engineering" can be resolved by concurrent engineering. Broadly defined, concurrent engineering is the simultaneous design of products and their engineering, manufacturing and marketing processes (Figure 9). In contrast to the serial approach, with concurrent approach to engineering, multifunctional teams attack all aspects of product development simultaneously. Information is released in incremental units, the batch size for information transfer from one design stage to the next is reduced to the smallest unit possible. As such this step is very similar to the batch size reduction in production lead time reduction. 


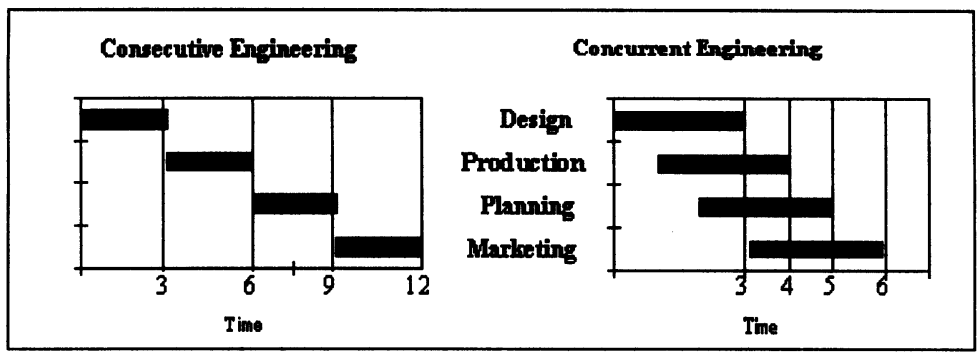

\section{Figure 9}

The major benefits of concurrent engineering are:

- Reduced cost of change

Catching mistakes early in new product development is very important, the later a change or revision is made the more expensive it is. During the initial phase the designer can make changes easily, often with little more than a few computer keystrokes. But later in the process, when the tooling for production has been made changes become very expensive. Business week has reported that the cost of change for a major electrical product increases with one order of magnitude with each phase of its development

- Reduced development lead time

However small batch information processing and concurrent engineering are not easy to implement and are accompanied with serious risks. Releasing partial information increases the likelihood that erroneous information is sent downstream. Flexibility of the team workers is very important because they will have to work with incomplete information. People from different departments will have to overcome their reluctance of working together and to release incomplete information to critical eyes. Modern information technology and severe procedures must be introduced to prevent people to work with outdated information,etc.

Experts say it may take two full product development cycles to realize most of the benefits associated with concurrent engineering.

\subsection{Setup time reduction}

A new product introduction can be seen as a changeover from an old product to a new one, and the goal is to make the transition as quickly and efficiently as possible. There are four basic activities that apply to changeover time reduction in new product development :

1. Internal versus external activities

SMED tries to reduce changeover times by performing as many activities as possible before or after the actual setup. Within new product development this can be achieved by performing development, manufacturing or marketing activities while the design phase is still being fine-tuned. Much of the work on manufacturing equipment or layout and on equipment procurement can be done during the design phase and hence be converted into off-line activities. These principles have been covered yet in the paragraph about concurrent engineering. 
2. Eliminate and simplify tasks

Every non value added activity must be identified and eliminated. Value added analysis has proven its usefulness in improving manufacturing processes. Early Time Based Competitors discovered that many of the delays in design, development and testing can be reduced by eliminating activities such as redesigning existing parts and prototyping.

Design engineers are prone to reinvent the wheel. However one of the easiest ways to reduce costs and save time is to use off-the-shelve components or common parts in different designs (i.e. commonality). Moreover an additional benefit of commonality will arise later in production.

When analyzing total new product development lead-time it is not unusual to see prototyping being responsible for $30 \%$ or more of total lead-time. As a consequence firms today are questioning the role of prototypes and are searching for alternatives, and finding them.

Modern technologies like solid modelling or simulation offer effective alternatives. Solid modelling for example allows designers to check fit, relative size, clearances and to get an idea of functionality. High resolution monitors provide very realistic images of designs which permit to evaluate aesthetics and make former clay models obsolete. Moreover solid modeling encourages (early) changes in the design.

Simulation and analysis software provide the ability to evaluate concepts while they are still bits in the computer. Using the geometry created by CAD, such software can analyze product performance and suggest areas for improvement. Finite elements analysis is generally considered the most valuable tool for this purpose. It is used for whole ranges of problems, from the usual structural analysis to thermal, dynamic, magnetic and fluid analysis.

When prototyping is unavoidable, NC-programming and rapid prototyping use a variety of technologies (e.g. stereolithography) to more directly turn CAD geometry into a physical part.

\subsection{Teamwork}

One of the greatest barriers to overcome in developing a concurrent engineering environment is the ability of people to get along and work with each other. Indeed, the small batch information processing approach places higher premium on teamwork than the conventional and sequential approach. As a firm moves toward overlapping activities information flows within and between departments become more complex and crossfunctional teamwork becomes increasingly important. The choice and training of the product development team has taken a critical dimension. One of the first steps to developing a cross-functional team is to break down the barriers that exist between specialties (Hammer and Champy[1993]). These teams are composed of people from marketing, sales engineering and manufacturing, who have no idea what the people from other groups do and how they perform. It is therefore necessary to train team members on how to operate.

\subsection{Information flow and layout}

In most companies, new product development is organized as a job-shop. Design is done in one area, drawings are then transmitted in batch to the next department in the pipeline 
(engineering) and so on. With concurrent engineering and cross-functional teams, people from different departments must be put together and work together simultaneously. This means that the layout must be reevaluated for every project in a process of ongoing improvement. People must get used to be relocated after each project. Managers must accept to dedicate their designers to small numbers (ideally one) of projects. Some companies even remove people from their home offices to put them at work together in isolation for the duration of the project.

\subsection{Automation}

Automation should be viewed as the culminating, not the initiating, activity in efforts to reduce development time. In accordance to the principle "Simplify first, then automate", automation is the last step in lead-time reduction programs. When automation is introduced without making the changes in the organizational structure or the design team, it may result in adding expensive technology that need to be restructured (islands of technology cause sub-optimality without improving global efficiency). In many companies $\mathrm{CAD} / \mathrm{CAM}$ procedures have merely automated the paper system without improving overall performance. One must not forget that when a drawing is idle, time is wasted no matter whether the drawing is idle in electronic form or in paper form. Figure 10 describes the different phases of design and their key technologies.

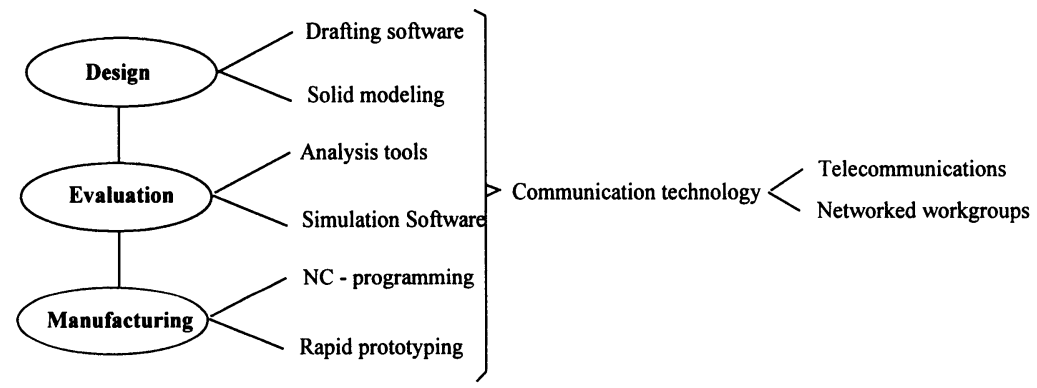

Figure 10

\subsection{Quality and continuous improvement}

Introducing quality in manufacturing means " Do it right the first time". For new product development this principle can be translated into " Do the early part right ". i.e. do the up.front work thoroughly even at the price of lengthening that phase, because correcting an error in a later phase can be very expensive. Many accounting people and budget cutters will likely scream at an approach that calls for thorough initial planning. They may say that the best time to save money is early in the project because that leaves a lot of time to revise things later ("We can always produce a few more " in large batch manufacturing). That is completely incorrect however. It is much more cost-efficient to spend the money up-front to do the job right.

Another guarantee of quality in JIT or time based manufacturing is provided by the small batch sizes and empowerment of workers. Thanks to small process and transfer batches products arrive quickly at the next workstation where faulty parts are identified. 
The operator has then the authority to stop the line and identify the cause of the defect. The same concepts apply to concurrent engineering where information and blueprints are released early to the next phase where mistakes, functional problems, etc. are detected. Within teams meetings are organized frequently to deal with these problems. The third dimension of quality is continuous improvement (KAIZEN, Imai [1986]) or, "learn from your mistakes". Senge [1990] recently emphasized the importance of organizational learning. Learning experience from each project should be gathered and passed on to the next project and so on. When development cycles are short, the learning cycle is accelerated creating a faster learning curve. Moreover as more emphasis is put on communication and contact between departments the information is spread faster and more efficiently.

And last but not least the (ten) concepts of quality and total design process control (Sleeckx [1993]) are summarized in Table 4.

\begin{tabular}{|c|c|}
\hline Concept & Technique(s) \\
\hline Listen to the customer & $\begin{array}{l}\text { - Quality function development } \\
\text { - Quality = what the customer wants } \neq \text { perfection !!! }\end{array}$ \\
\hline Work with product teams & $\begin{array}{l}\text { - Multi-disciplinarity } \\
\text { - Dedication and co-location } \\
\text { - Autonomous } \\
\text { - Concurrent engineering }\end{array}$ \\
\hline Integrate process design & $\begin{array}{l}\text { - Design for assembly } \\
\text { - Design for disassembly } \\
\text { - Design for manufacturing }\end{array}$ \\
\hline Optimize co-makership & $\begin{array}{l}\text { - Strong long term business relationships } \\
\text { - Concurrent engineering "over the walls" }\end{array}$ \\
\hline $\begin{array}{l}\text { Work with digital product } \\
\text { models }\end{array}$ & $\begin{array}{l}\text { - STEP (Standard for Exchange of Product data } \\
\text { - EDI (Electronic Data Interchange) } \\
\text { - Lotus notes or similar software }\end{array}$ \\
\hline Integrate $\mathrm{CAD} / \mathrm{CAM} / \mathrm{CAE}$ & $\begin{array}{l}\text { Integration } \neq \text { interfacing } \\
\text { - } \mathrm{CNC} \text { - rapid prototyping }\end{array}$ \\
\hline $\begin{array}{l}\text { Use simulation wherever } \\
\text { possible (correct mistakes } \\
\text { before you really make } \\
\text { them) }\end{array}$ & $\begin{array}{l}\text { - Aesthetic modelling in real world environment } \\
\text { (remember Jurassic park) } \\
\text { - Finite elements } \\
\text { - Interference control } \\
\text { - Kinematic analysis }\end{array}$ \\
\hline Use inherent quality control & $\begin{array}{l}\text { - FMEA (Failure Mode and Effect Aralysis) } \\
\text { - Taguchi methods }\end{array}$ \\
\hline Accelerate decision making & $\begin{array}{l}\text { - Lean management } \\
\text { - Autonomous teams }\end{array}$ \\
\hline Improve continuously & $\begin{array}{l}\text { - KAIZEN } \\
\text { - Learning cycles } \\
\text { - Deming wheel }\end{array}$ \\
\hline
\end{tabular}

Table 4

\section{CONCLUSION}

Just in time, fast cycle manufacturing, quick response, business process reengineering, concurrent engineering, agility, lead time management, lean manufacturing, time based 
competition, etc. whatever the name is, in essence it all boils down to the same: time. If you are able to bring competitive products faster to the customers than its competitors, you will get the deal. In the previous paragraphs we discussed some of the techniques available for lead time reduction and control within manufacturing and new product development. We choose these techniques among several others for two reasons: first because they are easy to implement in most environments without high investments and second because we successfully tested and implemented these techniques in projects conducted by the Center for Industrial Management in the process, the discrete and the service industry.

\section{BIBLIOGRAPHY}

Andries, B. and Gelders,L. (1995), Time Based Manufacturing Logistics, Logistics Information Management, Vol. 8, No. 3, pp. 30 - 36

Benjamin, R., Wigand, R. (1995), "Electronic Markets and Virtual Value Chains on the Information Superhighway", Sloan Management Review, pp. 62-72

Blackburn, J.D. (1991), Time-Based Competition - The Next Battle Ground in American Manufacturing, Business One Irvin, Homewood, Illinois

Choperena, A.M. (1996), Fast Cycle Time - Driver of Innovation and Quality, Research Technology Management, Vol. 39, No.3, pp. 36 - 40

Clark, K.B., Chew, B. and Fujimoto, T. (1987),"Product Development in the World Auto Industry", Brookings Papers on Economic Activity, Vol. 3,pp. 729-777

Gelders, L., Mannaerts, P. and Maes, J. (1994), Manufacturing Strategy, Performance Indicators and Improvement Programmes, Int. J. Prod. Res., Vol. 32, No. 4, pp. 797 805

Hammer, M. and Champy,J., (1993), Reengineering the Corporation, Harper Business, New York

Imai, M. (1986), KAIZEN: The Key to Japans Succes, Mc. Graw Hill, New York

McKinsey \& CO (1985), Triad Power : The Coming Shape of Global Competition, Flammarion, Paris

Meyer, C. (1993), Fast Cycle Time: How to Align Purpose, Strategy and Structure fir Speed, Free Press, Macmillan Inc., New York

Senge, P. (1990), The Fifth Discipline, Double Day, Doubleday Dell Publishing Group, New York, New York

Shapiro, B.P., Rangan, K.V. and Sviokla,J.J. (1992), Staple Yourself to an Order, Harvard Business Review, pp. $113-122$

Shingo, S. (1985), A Revolution in Manufacturing: The SMED System, Mass. Productivity, Cambridge

Skinner, W. (1974), The Focused Factory, Harvard Business Review, May-June 1974, pp. $113-121$

Stalk, G. (1990), Competing against time :how time based competition is reshaping global markets, Free Press, New York,

Stalk, G.JR. and Webber, A.M. (1993), Japan's Dark Side of Time Harvard Business Review, July -August 1993, pp. 93 - 103

Wiendahl, H.P.and Glassner, J. (1992), Petermann,D., Application of Load-Oriented Manufacturing Control in Industry, Production Planning Control, Vol. 3, No. 2, pp. $118-129$ 